\title{
Arbor
}

\section{Alteraciones del Relato}

\author{
Mercedes Belinchón, Patricia Insúa
}

Arbor CLXVII, 697 (Enero 2004), 157-187 pp.

La complejidad cognitiva que supone la producción de discursos y relatos ha sido puesta de manifiesto en la medida en que se ha reconocido que implica la planificación y generación por parte de un hablante de secuencias coherentes de enunciados con propósitos comunicativos, siendo así un ejemplo característico de actividad estratégica, guiada por metas, que exige la generación de planes y la toma de decisiones.

Desde la Lingüistica se han propuesto modelos de producción de los discursos que recogen intuiciones interesantes sobre procesos con potencial realidad psicológica. La integración del conocimiento y la gestión de la información van a ser dos problemas a los que el hablante deberá enfrentarse para construir un discurso coherente debiendo resolver con eficacia cuestiones como la gestión retórica, la gestión temática, la gestión referencial y la gestión del foco.

También desde la Lingüistica se han planteado nociones como cohesión, coherencia y macroestructura como niveles básicos de la «textualidad» de los textos, que han fundamentado el desarrollo de diferentes indices utilizados en los estudios empíricos sobre la producción del discurso.

La investigación realizada con grupos de sujetos con diferentes patologías (esquizofrenia, demencia tipo Alzheimer, lesiones cerebrales, trastornos del espectro autista, etc.), utilizando estos indices, han permitido objetivar los rasgos que diferencian los discursos juzgados como «normales» de aquellos que son juzgados como «desviados», aunque no han permitido obtener patrones diferenciados de alteración asociados a la patología concreta, evidenciando la limitación tanto de los indices como de las estrategias metodológicas. 
"Una de las maneras más sencillas de entender el
funcionamiento de un sistema es observar lo que
pasa cuando el sistema falla».

(PARKIN, 1999)

\section{Introducción}

El estudio sístemático de conductas o comportamientos alterados constituye una estrategia metodológica de larga tradición y probada utilidad a la hora de intentar dilucidar la compleja organización y funcionamiento del cerebro-mente humano. Así, por ejemplo, los errores lingüisticos cometidos por los pacientes afásicos (y, también, por hablantes clínicamente normales) empezaron a estudiarse a finales del siglo XIX y son considerados aún como fuente de información privilegiada para el estudio de la arquitectura y las constricciones del procesador lingüístico humano durante la producción del lenguaje. Las disociaciones de memoria observadas sistemáticamente en el síndrome amnésico constituyen una pieza determinante de los actuales modelos teóricos de la memoria humana, y validan de forma empírica (aunque ciertamente dramática) la necesidad de diferenciar sistemas múltiples de memoria. Los síntomas clínicos de personas con trastornos neuropsicológicos como la agnosia visual, la neglicencia y los síndromes frontales, o con trastornos neuropsiquiátricos como la esquizofrenia, las demencias o el autismo, han puesto a su vez de manifiesto (paradójicamente por su ausencia) componentes esenciales para la comprensión de funciones psicológicas complejas como la percepción visual, las funciones ejecutivas, y las habilidades de atribución mentalista (teoría de la mente), que sin duda serían difíciles de capturar en la investigación con sólo individuos "sanos" (ver Parkin, 1999; García-Albea e Igoa, 1999; Baron-Cohen, Tager-Flusberg y Cohen, 2000; Ruiz Vargas, 2002).

Mutatis mutandis, el estudio de discursos alterados (y concretamente el de narraciones/relatos considerados anómalos o producidos por personas con trastornos de algún tipo) podría ofrecer a los investigadores «una óptima oportunidad para desarrollar modelos dinámicos del cerebro y el lenguaje que expliquen de forma más completa la complejidad del empleo del lenguaje en los contextos sociales»(Bloom, 1994, p. ix). Hasta ahora, sin embargo, el impacto teórico de estos estudios parece ser insignificante, lo que puede atribuirse a la propia complejidad de los fenómenos discursivos y a la dificultad subsiguiente para desarrollar modelos operativos, empíricamente contrastables, de los procesos que permiten a los hablantes producir discursos narrativos ${ }^{1}$, o de cualquier otro formato, en tiempo real. 


\section{Complejidad y procesos de la producción de discursos.}

Como ha sido destacado con frecuencia (p.ej., Belinchón, Igoa y Rivière, 1992), el concepto de discurso es difuso y polisémico. Se aplica tanto para designar cualquier forma de «lenguaje en uso», como para designar diferentes clases de usos (p.ej., discurso político, científico, etc.). Se asocia con la producción verbal oral, y también con los textos escritos. Constituye un tipo de acción individual, sometida a las restricciones funcionales del sistema cognitivo y lingüístico humano, pero también una práctica social, sometida a las restricciones del contexto y la cultura.

La producción verbal de discursos (narrativos, descriptivos, etc.) implica la planificación y generación por parte de un hablante de secuencias coherentes de enunciados con propósitos comunicativos. Desde un punto de vista cognitivo, representa un ejemplo característico de actividad estratégica guiada por metas, que exige la generación de planes.

La producción de discursos entraña una dificultad cognitiva singular, porque exige integrar procesos múltiples de «alto nivel» (perceptivos, inferenciales y de memoria), característicos también de otras actividades complejas como la categorización, la comprensión de procedimientos y objetivos o la solución de problemas, y porque implica a la vez «procesos modulares» específicos del dominio lingüístico, tales como los que intervienen en la codificación morfo-fonológica de las frases y oraciones individuales (procesos de selección léxica, construcción del marco sintáctico de la oración, inserción de sufijos y partículas gramaticales, etc.). La participación integrada de procesos cognitivos modulares y centrales que caracteriza la producción de todas las formas de texto sitúa funcionalmente esta actividad en la interfaz del lenguaje y el pensamiento, y la convierte en una posible prueba de la «Primera Ley de Fodor sobre la Inexistencia de la Ciencia Cognitiva», que establece la imposibilidad de comprender científicamente los procesos cognitivos más globales e isotrópicos (Fodor, 1983). Por otro lado, la existencia de «tipos» de discurso formalmente muy diversos y la existencia de variaciones asociadas (entre otras) a la edad y la cultura (Obler y cols., 1994; Berman y Slobin, 1994) convierten el discurso en un fenómeno empírico multiforme y escurridizo en el que resulta difícil la detección y formalización de regularidades.

Como ha señalado recientemente Levelt (1999, p. 89), la pretensión de desarrollar modelos operativos capaces de diseccionar la enorme complejidad de los discursos resulta probablemente tan descabellada como la pretensión de «desarrollar una teoría termodinámica [capaz] de predecir el tiempo", y por ello no es de extrañar que, en el momento actual, se carezca todavía de un marco explicativo unificado que permita anclar el 
discurso tanto en las teorías de la cognición como en las de la acción social (van Dijk, 1997a; 1997b). A pesar de la desmesura de la pretensión, sin embargo, numerosos investigadores de distintas disciplinas (lingüistas, psicólogos cognitivos y programadores de Inteligencia Artificial) han ido identificando algunas de las principales piezas de este complejo rompecabezas, formulando algunos principios genéricos sobre las propiedades de los discursos/textos, y sobre las representaciones y procesos cognitivos implicados en su planificación/ejecución, que han permitido enmarcar los escasos estudios empíricos disponibles hasta la fecha.

\section{Propiedades de los discursos}

La actividad a que llamamos discurso participa de una serie de propiedades que la definen y diferencian de otras clases de actividad, y que sirven como punto de partida para distinguir también entre discursos o textos «normales», $\mathrm{y}$ «no textos» 0 «discursos patológicos». En términos de Belinchón, Igoa y Rivière (1992), las propiedades más destacables, para un análisis funcional de los discursos y textos, son las siguientes:

(a) Su carácter intencional, es decir, el hecho de que los discursos/textos realizan intenciones comunicativas de un hablante, que se pretende sean reconocidas por su interlocutor.

(b) Su carácter cooperativo, es decir, el hecho de que su eficacia comunicativa depende de la capacidad del hablante para tomar en cuenta tanto las creencias y expectativas de su interlocutor como el «conocimiento común» que ambos comparten.

(c) Su carácter contextualizado, es decir, el hecho de que «presentan» o expresan las actitudes y perspectiva del hablante, y que se ven influidos y constreñidos por la situación social e interpersonal en que se realizan.

(d) Su carácter supraoracional, es decir, el hecho de que constan de grupos o secuencias de enunciados interconectados, que desarrollan de forma ordenada un tema o significado global.

\section{Representaciones y Procesos}

La producción de discursos eficaces y bien formados implica, por parte del hablante, el acceso a fuentes muy diversas de información. Aparte del conocimiento de la lengua (competencia gramatical) y el conocimien- 
to general del mundo, los estudios cognitivos y lingüísticos sobre el discurso, y los programas de simulación desarrollados en el marco de la Inteligencia Artificial, destacan especialmente el empleo, por el hablante, de los siguientes tipos de conocimiento:

a) Conocimiento de los procedimientos de selección y jerarquización de intenciones $\mathrm{u}$ objetivos comunicativos y procedimientos para elaborar, implementar y revisar planes orientados a metas.

b) Modelo de oyente ( o «teoría de la mente» del interlocutor) y conocimientos de procedimientos para predecir la actividad de los interlocutores y regular el propio discurso atendiendo a dichas predicciones.

c) Conocimiento del «conocimiento mutuamente manifiesto» o «conocimiento común» de los interlocutores, que fundamenta el cálculo eficaz de las condiciones de relevancia de las contribuciones al discurso.

d) Modelo del discurso previo y conocimiento de los procedimientos que permiten regular el contenido informativo del discurso (equilibrio entre la información nueva y la dada).

e) Modelo del contenido pragmático o situación concreta en que se desarrolla el discurso.

f) Conocimiento de los principios conversacionales (vg. las máximas de Grice) que regulan los intercambios comunicativos.

g) Conocimiento de los formatos textuales básicos (narrativo, expositivo, etc.) y de sus correspondientes macroestructuras canónicas.

h) Conocimiento de los procedimientos que permiten mantener la textualidad (coherencia lineal y global) entre las unidades del texto.

i) Procedimientos para recuperar y re-utilizar conocimiento adquirido previamente a partir de textos.

j) Procedimientos para evaluar y manejar situaciones mediante el uso de textos lingüísticos.

k) Procedimientos para mantener el discurso a pesar de las discrepancias, discontinuidades, ambigüedades y ocurrencias no esperadas que puedan producirse.

La producción/generación de discursos, por otra parte, supone, por el hablante, la realización de tres grandes grupos de procesos (ver por ejemplo Levelt, 1989, 1999; Andriessen, de Smedt y Zock, 1996): 
(a) Procesos preverbales o de conceptualización, que implican tanto la selección de los contenidos que se pretenden comunicar como la planificación de su distribución jerarquizada a lo largo del texto;

(b) Procesos de codificación o formulación lingüistica, que se refieren a la preparación de los marcos sintácticos y morfo-fonológicos de las frases y palabras individuales de los textos; y

(c) Procesos de realización articulatoria, que permiten la generación o producción efectiva del habla.

La naturaleza exacta de los procesos preverbales del discurso, así como el tipo de relación funcional que mantienen con los procesos de niveles inferiores (codificación y articulación) durante la producción en tiempo real representan para el investigador un problema «horrorosamente complejo» (Levelt, 1999, p. 89), que está lejos de estar resuelto. Desde el ámbito de la Lingüística textual, sin embargo, se han esbozado algunas propuestas que contienen intuiciones interesantes sobre procesos con potencial realidad psicológica.

La propuesta pionera de van Dijk (1980), por ejemplo, interpreta que el proceso de producción de los discursos se inicia con la elaboración de una representación general que contiene información tanto del acto de habla global (o intención comunicativa) como del tópico principal a desarrollar a lo largo del discurso. Esta representación general es denominada por él «macroproposición», y su elaboración implica la activación de la información de la memoria a largo plazo a partir de la información situacional y de los otros discursos previos. La macroproposición con la que se inicia un discurso, según van Dijk, se almacena temporalmente en la memoria a corto plazo (memoria operativa) y actúa como una «representación-base» desde la que se generan representaciones temáticas más específicas (los subtópicos). Estos subtópicos, a su vez, constituyen el input potencial de la codificación lingüística de los párrafos y/o de las oraciones y son ordenados jerárquicamente en función de su relación con el tópico central. La representación de esta jerarquía se mantiene también activada en la memoria a corto plazo u operativa. Desde ahí, suministran la información necesaria y controlan la ejecución efectiva del plan discursivo.

La propuesta formulada por Beaugrande (1980) coincide con la de van Dijk en la idea de que el inicio de la producción de un discurso presupone por parte del hablante la elaboración de una representación inicial global (el «modelo del texto»), que sintetiza el conocimiento vehiculado y activado por el discurso previo: a diferencia de van Dijk, sin embargo, Beaugrande interpreta que este «modelo del texto» se inserta en un «mo- 
delo de situación», y que el sistema necesita un «umbral de terminación» que determine cuándo están realizadas las intenciones comunicativas y cuándo, por tanto, debe concluirse el proceso.

Una última propuesta de interés, más actual y detallada, es la de Tomlin y cols. (1997), quienes sostienen que construir un discurso requiere, por el hablante, enfrentarse a dos problemas fundamentales: el problema de la integración del conocimiento, esto es, la selección de los conceptos y sucesos pertinentes de su experiencia y su organización en un modo útil para su comprensión por el oyente; y el problema de la gestión de la información, que se refiere al hecho de que hablante y oyente deben manejar el flujo de la información como una interacción dinámica en tiempo real, y a que la forma en que el hablante controla el flujo de información hacia el oyente (Chafe, 1979; 1980; 1987; 1994) va a determinar la facilidad con la que éste puede integrar este conocimiento en un modelo mental coherente.

La gestión de la información en la producción de los discursos implica, en el modelo de Tomlin al menos cuatro cuestiones independientes: (a) el problema de la gestión retórica; (b) el problema de la gestión temática; (c) el problema de la gestión referencial, y (d) la gestión del problema del foco del discurso (Fig.1).

FIgURa 1. Esquema de la producción del discurso (tomado de Tomlin et. al., 1997)

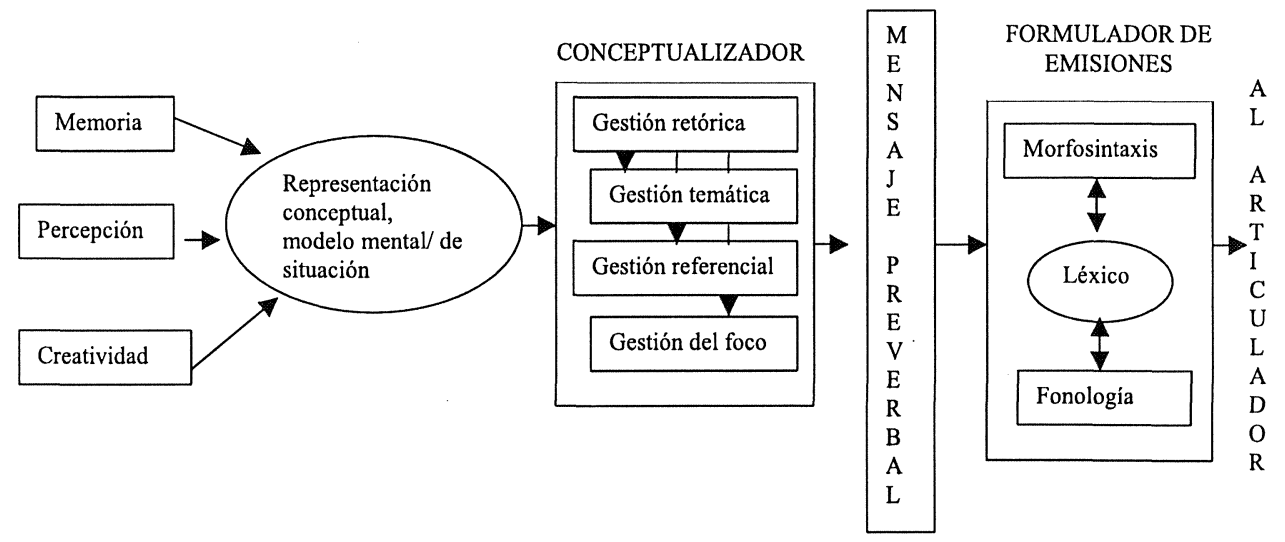

(a) Gestión retórica. En el momento de iniciar su discurso, el hablante tiene una meta o propósito comunicativo (o incluso varios). Estas metas constriñen la forma en que se exploran las representaciones conceptuales y restringen la información a comunicar. Son 
consideradas por algunos autores como «metas retóricas» y resultan importantes para la semántica del discurso por varias razones: porque la producción del discurso implica enunciados lingüísticos integrados según consideraciones de orden superior; y porque las metas retóricas juegan un papel importante en la codificación morfosintáctica de los enunciados y en la asignación de los marcadores que señalan los diferentes estados de la información durante el progreso del discurso (Chafe, 1994; Givón, 1991; 1992).

(b) Gestión temática. A la hora de planificar el discurso, el hablante toma decisiones en tiempo real acerca de qué referentes y proposiciones son más centrales o importantes para el discurso. Esta jerarquización de los referentes determina la «organización temática» del discurso e implica una serie de procesos pragmáticos asociados. La cuestión fundamental en la gestión temática tiene que ver con la centralidad de ciertos conceptos y proposiciones que van a proporcionar el marco en torno al cual se ubican los detalles del discurso. Las nociones de tópico o tema clausal, tema del hablante o del discurso, y marco del tema serían algunos conceptos clave para el análisis de la gestión temática (Perfetti y Goldman, 1974; Brown y Yule, 1983).

(c) Gestión referencial. De forma paralela a la gestión del tema, el hablante debe controlar dinámicamente qué referentes y proposiciones están ya disponibles para el oyente y cuáles requieren una reintroducción o una nueva introducción. Estos referentes y proposiciones se distribuyen básicamente en dos clases: las que el hablante cree que están fácilmente al alcance del oyente (la información «dada») y aquellos acerca de los cuáles el hablante cree que el oyente necesitará una asistencia explícita para acceder a ellos (la información «nueva») (Haviland y Clark, 1974; Brown y Yule, 1983).

(d) Gestión del foco. A lo largo de su discurso, el hablante debe controlar también de manera dinámica qué referentes y proposiciones desea que sean llevados a la atención del oyente, destacando o enfatizando alguno en particular. El foco del discurso es la información que se destaca de otra información (Longacre, 1976) a través de mecanismos tales como la entonación, el orden de los constituyentes o los marcadores morfológicos. Estudiado por la Escuela de Praga con su distinción «tema/rema», recientemente la cuestión del foco ha sido investigada también por Lambrecht (1994), para quien el foco sería aquél trozo de la proposición que 
se asevera (esto es, lo que se espera que el oyente sepa o dé por hecho como resultado de escuchar la oración emitida), en contraste con la información presupuesta, esto es, con lo que el hablante supone que el oyente ya sabe o da por hecho. Con un abordaje experimental, Levelt $(1982,1989,1999)$ ha abordado también el problema de la "gestión del foco» y confirmado su carácter de proceso que se rige por un grupo muy reducido de reglas.

\section{El análisis empírico del discurso: Aspectos metodológicos.}

La diversidad de visiones y distinciones teóricas desarrollados por los lingüistas al objeto de identificar las características distintivas de los discursos y los procesos cognitivos que requiere su producción no se han visto acompañados (fuera del ámbito de la Inteligencia Artificial) de un desarrollo paralelo de estrategias y paradigmas de investigación que permitan el análisis empírico de los discursos naturales y la comparación, en su caso, de los discursos «anómalos» y «normales».

Salvando los estudios con tareas de comunicación referencial ideadas por Krauss y Glucksberg a finales de los 60 (que emulan con cierta eficacia el carácter cooperativo y dinámico de los discursos espontáneos), y los que emplean tareas de producción elicitada de oraciones en condiciones experimentales restringidas (como la descripción de series más o menos complejas de figuras o dibujos -ver Levelt, 1989-), el grueso de las investigaciones empíricas sobre discurso se ha basado en la grabación y transcripción de textos más o menos espontáneos (conversaciones, descripciones de láminas y secuencias de dibujos, generación de relatos o repetición de historias previamente oídas o leídas), y se ha centrado en el análisis de su organización intratextual, en los tres niveles fundamentales recogidos por los modelos lingüísticos: la cohesión, la coherencia y la macroestructura de los discursos.

\section{(a) Cohesión}

Para algunos autores como Halliday y Hasan (1976), la posibilidad de que una secuencia de emisiones lingüísticas pueda ser interpretada como un «texto» y no como un conjunto aleatorio de enunciados se deriva de la presencia, en la estructura superficial de éstos, de una serie de dispositivos lingüísticos -los llamados vínculos de cohesión- que relacionan y conectan unas oraciones con otras. El concepto de cohesión, como observan estos autores, explica el significado de relaciones que se dan en el discurso y se refiere «al conjunto de recursos que se pueder, utilizar para po- 
ner en relación una oración con las que se han presentado antes [en el texto]» (Halliday y Hasan, op. cit., p. 10). Estos recursos incluyen marcas morfosintácticas específicas (mecanismos de coordinación, subordinación gramatical, concordancias, etc.) pero también mecanismos tales como la elipsis, la referencia y las repeticiones léxicas (ver ejs. en Tabla I).

TABLA I. Ejemplo de los vínculos de cohesión y de sus principales categorías, según Halliday y Hasan (1976)

\begin{tabular}{|c|c|c|}
\hline Categoría & Subcategoría & Ejemplo \\
\hline \multirow[t]{3}{*}{ Referencia } & 1. Pronominal & Nos encontramos con Luis y cenamos con él \\
\hline & 2. Demostrativa & $\begin{array}{l}\text { Fuimos a una fiesta y....bueno; aquello fue la } \\
\text { locura! }\end{array}$ \\
\hline & 3. Comparativa & $\begin{array}{l}\text { Se me acercaron tres tipos extraños. El más } \\
\text { bajo me preguntó si llevaba fuego. }\end{array}$ \\
\hline \multirow[t]{3}{*}{ Elipsis } & 1. Nominal & $\begin{array}{l}\text { Tiene mucha energía. Desde luego tiene } \\
\text { mucha más * que yo. }\end{array}$ \\
\hline & 2. Verbal & $\begin{array}{l}\text { Querría quedarme aquí toda la vida: }{ }^{*} \text { dejar de } \\
\text { trabajar, * dejar de aguantar al jefe....... }\end{array}$ \\
\hline & 3. De cláusula & ¿Conoces Boston? Yo no, pero mi hermana sí *. \\
\hline \multirow[t]{4}{*}{ Conjunción } & 1. Aditiva & $\begin{array}{l}\text { Leí un libro la semana pasada } y \text { me gustó } \\
\text { bastante. }\end{array}$ \\
\hline & 2. Adversativa & $\begin{array}{l}\text { Querían ir a Barcelona pero el avión no pudo } \\
\text { aterrizar por la niebla. }\end{array}$ \\
\hline & 3. Causal & No vino porque prefirió ir al cine. \\
\hline & 4. Temporal & $\begin{array}{l}\text { Estuve un rato con Alicia, luego me acerqué al } \\
\text { Rastro. }\end{array}$ \\
\hline \multirow[t]{4}{*}{ Léxica } & 1. Igual raíz & $\begin{array}{l}\text { Mi hermano necesita independizarse. Depende } \\
\text { demasiado de mi padre. }\end{array}$ \\
\hline & 2. Sinónimo & $\begin{array}{l}\text { Siempre miente. Además se cree que no nos } \\
\text { damos cuenta de que nos engaña. }\end{array}$ \\
\hline & 3. Supraordinada & $\begin{array}{l}\text { Me encanta el pescado fresco. El otro día comí } \\
\text { un salmón exquisito. }\end{array}$ \\
\hline & 4. Ítem general & $\begin{array}{l}\text { Se fue la luz. La lámpara de mi habitación } \\
\text { chisporroteó u momento y después todo se } \\
\text { volvió oscuro. }\end{array}$ \\
\hline
\end{tabular}

Para referirse a una única instancia de cohesión, que es la ocurrencia de un par de ítems cohesivamente relacionados, Halliday y Hasan (1976) usan el término «lazo» (tie). Cualquier segmento de un texto puede ser caracterizado en término del número y tipos de lazos cohesivos que muestra, lo que aporta un índice operativo para el estudio empírico de los textos y la comparación posterior por condiciones y grupos. En el sistema que propone Halliday (1967a; 1967b; 1970; 1973; 1975; 1985), la cohesión es vista como parte del sistema del lenguaje, y como tal se expresa a 
través de lo que el autor ve como una organización del lenguaje en estratos. Describe el lenguaje como un sistema múltiple implicando tres niveles de codificación o estratos: el semántico (significados), el lexicogramático (las formas) y el fonológico y ortográfico (las expresiones). Los significados se codifican como formas y las formas se recodifican como expresiones, o en otras palabras, los significados se ponen en palabras y las palabras se ponen en sonidos o en escritura. En el estrato lexicogramatical no existe distinción clara entre vocabulario y gramática. Los significados más generales son expresados a través de la gramática y los más específicos a través del vocabulario. Los lazos cohesivos pueden encajar en este patrón y así, unos lazos son "gramaticales» y otros son «léxicos», pero esto no implica que sólo hay relaciones formales implicadas en tales lazos. Desde aquí la cohesión es vista como una relación semántica que es codificada a través de formas y las formas pueden ser léxicas o gramaticales.

El mecanismo cohesivo por excelencia es el uso de las formas pronominales. Cuando se utiliza una forma pronominal después de la expresión correferente, estamos ante una anáfora; cuando la forma pronominal antecede la expresión correferente, estamos ante una catáfora (Halliday y Hasan, 1976; Hankamer y Sag, 1976). La organización anafórica del texto suele ser el modo más habitual de construir la correferencialidad y es el procedimiento más económico para mantener activado durante un mayor espacio de tiempo el contenido conceptual de una expresión. Por esta misma razón, la organización anafórica del texto puede propiciar algún problema interpretativo cuando entre la expresión referencial y la forma pronominal se interpone un fragmento textual excesivamente amplio (Givón, 1983), especialmente si no se mantiene el antecedente en el foco de atención (Garrod y Sanford, 1982; Anderson, Garrod y Sanford, 1983).

(b) Coherencia

\section{b.1. Coherencia local}

El concepto de coherencia puede identificarse en primer lugar con la existencia de (o con la posibilidad de que el oyente reconozca) ciertas relaciones locales entre las proposiciones individuales constituyentes de un discurso. Aunque la naturaleza de estas relaciones no cuenta con una definición unívoca, van Dijk (1985) ha identificado algunas de las condiciones que requiere la coherencia. Así, sostiene que se debe especificar primero la acción más global posiblemente con indicación del tiempo y espacio, y luego se deben aportar los detalles de la acción o hechos mencionados. Así, en frases como: 
(1) a. El próximo mes estaremos en Bilbao

b. Nos quedaremos con unos amigos.

no sería coherente cambiar el orden de las oraciones, ya que éste debe reflejar el orden general-particular de los hechos o estados mencionados. Igualmente, el orden espacial entre los hechos requiere el mismo orden lineal en la expresión de las proposiciones. En frases como:

(2) a. Tienen una casa enorme en la colina

b. Tiene al menos 10 habitaciones

los objetos deben ser introducidos antes que las propiedades. Además, en la representación de las relaciones temporales y condicionales entre eventos o acciones, las condiciones posibles, probables o necesarias (por ejemplo causas) deben, en general, ser mencionadas antes que sus consecuencias, como en (3) y (4):

(3) a. Esta mañana tuve dolor de muelas

b. Fui al dentista

(4) a. Fuimos a un restaurante muy bueno

b. Juan pidió trucha con almendras

En el trabajo de Hobbs (1978, 1979, 1983), la coherencia local de los textos se deriva de la existencia de ciertos tipos de relaciones entre cada proposición del discurso y las proposiciones inmediatamente precedentes y/o posteriores (p.ej., la relación de elaboración, especificación, generalización). Estas relaciones de carácter binario constituyen un conjunto finito de opciones de las que el hablante puede hacer uso al "pasar» de un enunciado al siguiente durante la realización de discursos, y se ilustran en la Tabla II.

TABLA II. Relaciones básicas de coherencia lineal entre proposiciones, según Hobbs (1978, 1979 y 1983)

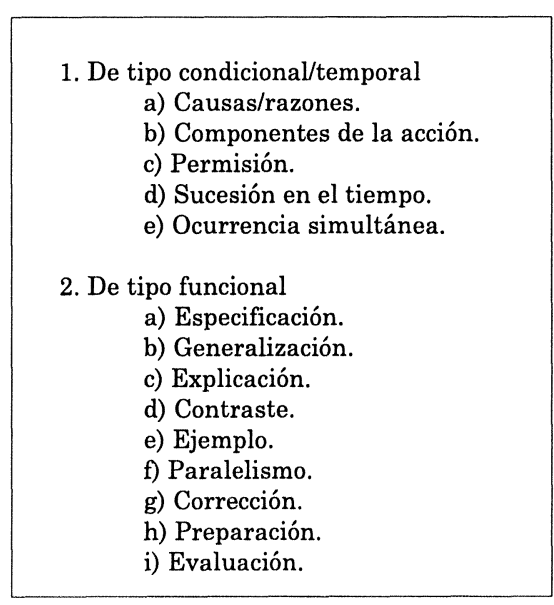




\section{b.2. Coherencia global: Macroestructura y superestructura.}

Que las oraciones en una secuencia estén conectadas linealmente (una a una) no es una condición necesaria ni suficiente para lo que intuitivamente se entiende como «coherencia textual». La significatividad del discurso reside no sólo en este nivel local de conexiones entre oraciones y cláusulas inmediatas (el nivel de la microestructura) sino también a nivel global (macroestructura y superestructura). La macroestructura de un discurso se refiere al contenido o significado global del discurso, y la superestructura se refiere a la organización particular de cada tipo de discurso (van Dijk, 1980).

La macroestructura de un discurso dado es una función de los significados respectivos de sus oraciones, pero exige un tipo de transformación semántica que empareja secuencias de proposiciones en el texto con secuencias de macroproposiciones más abstractas, generales o globales. Estos emparejamientos implican operaciones de supresión, generalización y construcción que son denominadas «macrorreglas» (Beaugrande y Dressler, 1981; van Dijk, 1985).

Algunos discursos y textos (y de forma especialmente marcada, los relatos narrativos) presentan regularidades macroestructurales características, fijadas culturalmente, a las que se suele denominar superestructura. En el caso de los textos narrativos, la superestructura o esquema básico macroestructural se compone de cinco categorías jerárquicamente ordenadas (ver Fig. 2), que constriñen la organización semántica del discurso, y por extensión, la de sus párrafos y oraciones constituyentes.

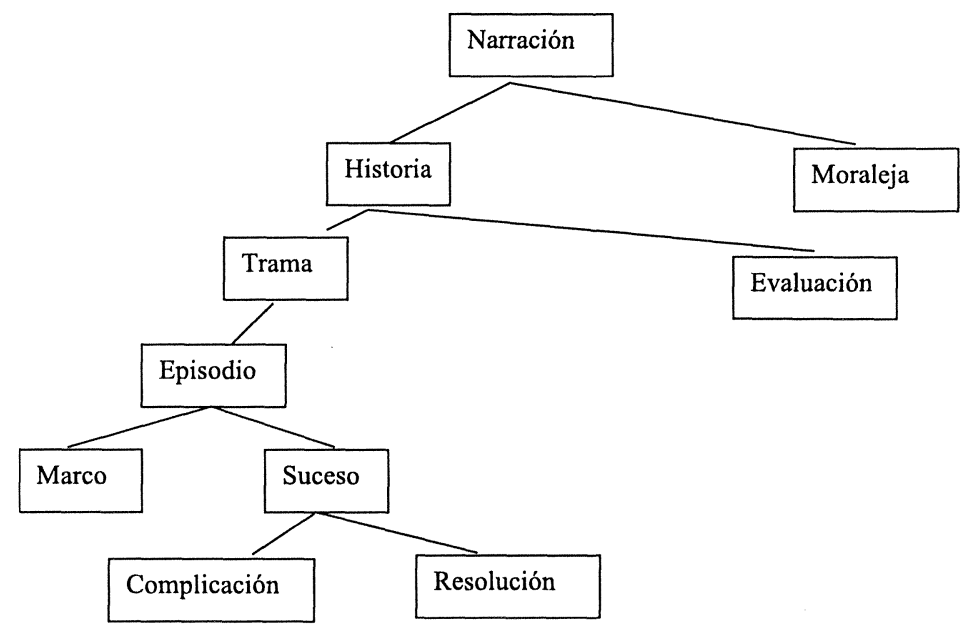

Figura 2. Diagrama de la superestructura de un texto narrativo (tomado de van Dijk, 1983) 
Los relatos narrativos, en definitiva, implican canónicamente la descripción por el hablante de una secuencia de hechos (auténticos o ficticios), que acontecen en un contexto determinado (personajes, lugares y tiempos), y que deben ser presentados al oyente con una lógica temporal y jerárquica determinada. En contraste con otros géneros textuales, los relatos narrativos implican marcas temporales definidas, y permiten identificar tanto al narrador del relato (primera o tercera persona) como su perspectiva (interna/externa).

\section{Alteraciones del discurso narrativo: Algunos hallazgos empíricos}

La investigación empírica de los discursos/textos narrativos realizada hasta la fecha parece haberse guiado por dos supuestos implícitos: (1) el supuesto de que las personas con alteraciones o trastornos psicológicos que afectan a funciones o mecanismos supuestamente implicados en la producción de discursos (atención, memoria, lenguaje, habilidades sociales, etc.) producirán, probablemente, discursos diferentes a los de personas sin alteraciones; y (2) el supuesto de que los discursos juzgados como anómalos o patológicos presentan desviaciones características (cuantitativas o cualitativas) que pueden ser capturadas mediante procedimientos de análisis formal (lingüístico).

El primero de estos supuestos genera un primer problema empírico (el de la constatación objetiva de diferencias lingüísticas significativas entre grupos patológicos y de control), y determina que, para el estudio científico del discurso, resulten tan sólo relevantes los datos de unos grupos muy concretos de pacientes (p.ej., pacientes con alteraciones clínicamente significativas en el sistema de memoria operativa -directamente ligado al control consciente de la actividad y a la atención, y que hipotéticamente permite el acceso y utilización coordinada de los distintos tipos de información requeridos por los discursos-, o personas con dificultades para el desarrollo y utilización en tiempo real de las capacidades de atribución mentalista-supuestamente necesarias para el cálculo eficaz de la relevancia-).

$\mathrm{El}$ primero de los supuestos añade un problema metodológico (el del grado de sensibilidad de los índices textuales para diferenciar entre discursos producidos por grupos con trastornos neuropsicológicos distintos) a lo que de por sí es un problema más básico, a saber, asumir como ha observado van Dijk (1983), que los hablantes producen habitualmente discursos relevantes y coherentes, con una macroestructura clara y una estructura retórica y estilística adecuadas. 


\section{Alteraciones del Relato}

El análisis de las formas patológicas en el ámbito del discurso, señala van Dijk:

«... es una labor muy delicada, que a lo sumo permite sacar ciertas conclusiones en los casos más claros. No podemos declarar que alguien que narre una historia incoherente o diga tonterías esté listo para ser internado. Las fronteras son borrosas, las normas son relativas y las convenciones poco seguras, lo cual no simplifica la descripción de eventuales patologías. No obstante, los trastornos psíquicos suelen deducirse precisamente de estas particularidades en la utilización compleja de la lengua, suponiéndose equivocadamente que los modelos de comunicación anómalos son indicadores seguros de estructuras y procesos mentales 'anómalos'. Los siguientes párrafos deben leerse, pues, bajo el signo de esta advertencia” (van Dijk, op. cit., p.231).

El elevado número de grados de libertad de que dispone el hablante en los niveles iniciales de la planificación del texto (que impide cualquier juicio normativo), el carácter regulativo (más que estrictamente constitutivo) de las reglas y principios que organizan el discurso (Searle, 1969), $\mathrm{y}$, sobre todo, el hecho de que la «coherencia» de un texto se deriva de su diseño lingüístico pero también (sobre todo) de las operaciones cognitivas que realiza el oyente sobre él, son otros factores que limitan el valor teórico de la información obtenida en el estudio de discursos alterados.

Los estudios sobre textos alterados (narrativos y de otros tipos) a que nos referiremos en este trabajo conciernen a grupos con patologías definidas que hipotéticamente comprometen procesos cognitivos contemplados por los modelos del discurso. Lejos de poder interpretarse, sin embargo, como estudios «guiados por las teorías», los trabajos que comentaremos (que ilustran, pero no agotan, la evidencia disponible en este campo) se iniciaron mayoritariamente por razones de tipo clínico que serán ignoradas en nuestra revisión.

\section{Alteraciones del discurso y esquizofrenia}

El estudio del discurso esquizofrénico se inició a principios del siglo $\mathrm{XX}$ y resultó en realidad paralelo a la propia delimitación del concepto de esquizofrenia. Desde que en las primeras descripciones clínicas de esta enfermedad (Bleuler, 1911/1960; Kraepelin, 1919/1971) se interpretara el «desorden formal del pensamiento» como uno de sus síntomas nucleares, la definición de la esquizofrenia se ha vinculado históricamente a rasgos tales como la «incoherencia», la «falta de comprensibilidad del habla» o el «descarrilamiento de las ideas en el discurso».

«El término esquizofrenia -afirman Rochester y Martin (1979)- fue acuñado en parte para describir las alteraciones en el discurso. En 1911 Eugen Bleuler comunicó su 
experiencia de confusión en tanto que oyente, ante los sujetos que hablaban incoherentemente. Comentó haber tenido dificultades para comprender el habla de los pacientes y describió un habla en el que ...las ideas se conectan de modo ilógico... y donde... inesperadamente, aparecen ideas nuevas que ni el paciente ni el observador pueden poner en relación con el curso anterior del pensamiento... [Desde entonces] ...esas alteraciones del discurso han sido interpretadas como indicadores de una ruptura de las funciones psíquicas, como lo [propiamente] 'esquizo " de la esquizofrenia" (op. cit. pág. 2-3)

Desde hace más de ocho décadas, el análisis de las verbalizaciones bizarras e incoherentes de los pacientes esquizofrénicos ha sido privilegiado en la clínica y las investigaciones, y considerado como el caso más prototípico de discurso patológico. Sin embargo, el intento de derivar marcadores objetivos de alteración discursiva específicos de los esquizofrénicos, y por consiguiente distintos o nunca presentes en los hablantes «normales», a partir de la observación de la «masa de producciones verbales» de estos pacientes (en expresión de Tucker y Rosenberg, 1975), ha tenido escaso éxito empírico.

Los primeros estudios sistemáticos del llamado «lenguaje esquizofrénico» se basaron en juicios clínicos (p.ej., Siegel y cols., 1976; Andreasen, 1979a; 1979b) y pusieron de manifiesto, en contra de lo esperado, (a) que los signos lingüísticos asociados al «desorden formal del pensamiento» (la incoherencia, la tangencialidad o el descarrilamiento de las ideas en el discurso) no son rasgos universales en los pacientes esquizofrénicos, y (b) que los textos juzgados como «esquizofreniformes» resultan indistinguibles de los textos producidos por pacientes con otras patologías (p.ej., pacientes con trastornos maníaco-depresivos), y pueden ser producidos también por hablantes sin patología alguna en condiciones de alta fatiga.

En la década de los 70, el interés de los investigadores por el estudio de la conducta lingüística desviada de algunos pacientes esquizofrénicos aumentó de manera espectacular. En 1974, por ejemplo, la lingüista Elaine Chaika (1974) presentó un estudio de gran impacto sobre una paciente que hablaba de forma normal excepto en los episodios agudos (en los que llegaba a monologar, hablando para ella misma, y sin permitir interrupciones). A partir del análisis de este caso, Chaika identificó como características del lenguaje esquizofrénico: los neologismos, los farfulleos (gibberish), la preferencia por la utilización del significado dominante de las palabras independientemente del contexto, el empleo de cadenas asociativas no subordinadas a un tópico (glossomanía), el empleo de rimas y aliteraciones inapropiadas para el tópico del discurso, la perseveración inadecuada de palabras o morfemas, la disrupción severa de la habilidad para aplicar las reglas sintácticas, y la incapacidad para darse cuenta de los propios errores gramaticales cuando éstos ocurren. 
La misma autora sostuvo, en trabajos posteriores (Chaika, 1981; 1982), que estas características podían interpretarse como manifestaciones de tres disfunciones básicas: la tendencia a la perseveración, la falta de control sobre la selección de las unidades lingüísticas durante el proceso de producción, y la incapacidad para subordinar las decisiones léxicas a las exigencias estructurales y comunicativas impuestas por el tópico del discurso.

Atendiendo al carácter mixto (gramatical y no gramatical) de las alteraciones observadas en la esquizofrenia, Chaika propuso asimilar el lenguaje esquizofrénico a una "afasia intermitente», lo que fue recibido con controversia por otros investigadores, ya que mientras algunos autores (p.ej., Benson, 1973; Gerson, Benson y Frazier, 1977; Lecours y Vanier-Clement, 1976) se alinearon con Chaika, otros (p.ej., Brown, 1973; Fromkin, 1975) prefirieron sostener que las conductas descritas reflejan un "pensamiento esquizofrénico» (es decir, un efecto de alteraciones en procesos cognitivos más centrales) y no tanto un «lenguaje esquizofrénico» (es decir, un efecto de problemas en el sistema de conocimiento/procesamiento lingüístico).

La posibilidad de dirimir entre estas dos alternativas resultó felizmente favorecida por la emergencia en esos años de la propia Lingüística textual y el desarrollo de índices que permitían evaluar, de forma más objetiva, la coherencia o incoherencia de los textos «esquizoafásicos». La nueva estrategia metodológica comenzó a aplicarse esos mismos años, de la mano de Sherry Rochester y sus colaboradores en el Institute Clarke of Psychiatry de Toronto. Los trabajos principales de este grupo (condensados en Rochester y Martin, 1979), partían inicialmente de la observación de dos hechos fundamentales: a) que no todos los esquizofrénicos se comportan como esquizoafásicos, y b) que no todos los esquizoafásicos lo son durante todo el tiempo. Aceptado el carácter episódico de la «esquizoafasia», el reto metodológico para los investigadores consistió, a partir de entonces, en capturar los episodios en que esta esquizoafasia se produce, y en tratar de objetivar sus características en base a parámetros compatibles con los modelos coetáneos sobre el discurso.

Los estudios realizados por el equipo de Rochester, al igual otros trabajos posteriores (p.ej., Chaika, Lambe y Alexander, 1982; Wykes y Leff, 1982; Harvey, 1983; Andreasen y cols., 1985) se centraron primariamente en los vínculos de cohesión y tomaron como referencia la propuesta de clasificación de Halliday y Hasan (1976).

Comparando episodios juzgados como alterados y no alterados, Rochester y Martin (1979; Rochester, Martin y Thurstone, 1977) encontraron dos tipos de fallos en el discurso que distinguen ambas clases de epi- 
sodios: por un lado, una fuerte dependencia del significado léxico para conseguir cohesión entre cláusulas y oraciones, y por otro, la tendencia del hablante a confiar en las características prosódicas de las cláusulas y las palabras para ligar estas cláusulas con el contexto previo. Los hallazgos, replicados posteriormente, parecen estar relacionados con una tercera característica del discurso de los sujetos con trastorno del pensamiento: las dificultades del que escucha para seguir el discurso del sujeto como consecuencia de la tendencia de éste a confiar en una alta proporción de referencias implícitas en las cuáles los referentes son frecuentemente oscuros incluso hasta la inaccesibilidad.

Rochester y Martin interpretaron sus resultados en el marco teórico propuesto por Halliday y Hassan (1976) sobre los «sistemas de foricidad». Basándose en estas ideas, sostuvieron que el hablante (esquizofrénico o no) procesa los significados contenidos en las expresiones haciendo elecciones en un determinado número de sistemas de lenguaje: expresiones fonológicas, formas léxico-gramaticales y significados semánticos en el texto. Asumieron que el hablante competente adulto puede producir textos coherentes tomando decisiones apropiadas en cada uno de estos estratos, si bien cuando está sometido a factores que reducen el control sobre el procesamiento del lenguaje (fatiga, estrés, ansiedad, etc.) fallará en la producción de discursos coherentes en ciertas maneras que son ordenadamente predecibles. Así, (a) primero, va a fallar a nivel de ligamiento entre oraciones, observándose una falta de dirección en el tópico, fallos en establecer líneas claras de eventos, y falta de ciertos tipos de cohesión entre cláusulas; (b) los fallos siguientes incluirían los anteriores y además errores en el nivel léxico-gramatical, de modo que se encontrarían neologismos, formas gramaticales inadecuadas, y el uso de palabras inapropiadas de varios tipos -las características prosódicas del habla, sin embargo, permanecerían más o menos intactas-; (c) finalmente, se produciría una completa ruptura en los mecanismos del lenguaje, que se evidenciaría en la incapacidad del hablante de emparejar los patrones de entonación o seleccionar palabras que rimen cuando se le pide que lo haga.

La hipótesis de que en la esquizofrenia se producen déficits de control que reducen la capacidad para la planificación y gestión del discurso, pero no necesariamente la capacidad para estructurar unidades lingüísticas menores tales como oraciones y palabras individuales, ha sido sometida a prueba por nuestro equipo (Belinchón, 1988; Anula, 1998; Insúa, Grijalvo y Huici, 2001) en diversos estudios recientes.

Centrándose en el análisis de dos narraciones elicitadas, y empleando medidas tanto de cohesión como de coherencia local y global, Be- 
linchón (1988) obtuvo en primer lugar diferencias estadísticamente significativas entre un grupo de 20 pacientes esquizofrénicos (con niveles bajos y medios de desorden formal del pensamiento) y 20 sujetos de control (sin ningún trastorno clínico) en un grupo muy amplio de indicadores. En el estudio se usaron tres tareas narrativas (narración de una historia presentada en vídeo, relato de una historia oída previamente, relato de la secuencia de acciones necesaria para la resolución de un problema -discurso procedimental) y textos de otros formatos.

En el grupo de sujetos con esquizofrenia, por ejemplo, se apreciaron menos vínculos de cohesión por oración (especialmente vínculos de referencia endofórica), mayor distancia de los vínculos de cohesión entre sí, mayor cantidad de anáforas ambiguas para el oyente, porcentaje mayor de proposiciones con vínculos de coherencia omitidos o incoherentes, menor número de unidades obligadas por la superestructura, y otras diferencias significativas en el ámbito de la organización morfosintáctica. En este mismo trabajo, la distancia entre los vínculos de cohesión y la suma de proposiciones sin vínculos de coherencia local compusieron una función discriminante que explicaba el $35,75 \%$ de la varianza total y clasificaba correctamente en sus grupos al $82,4 \%$ del total de los participantes en el estudio ( $74,7 \%$ de los esquizofrénicos y $100 \%$ de los controles). El cálculo de correlaciones resultó también significativo mostrando con claridad que el grado de organización de los textos de los esquizofrénicos, tanto en el nivel de su organización discursiva (coherencia, cohesión y macroestructura) como en el de su organización sintáctica, guardaba una relación funcional estrecha con fenómenos atencionales (como la capacidad de mantener focalizada la atención en una tarea no automatizable) que resultan fundamentales para el control cognitivo de la actividad (incluida la actividad lingüística), y que son centrales en el sistema de memoria operativa (ver Ruiz Vargas, 1993, para un análisis en profundidad de la noción de control y el papel de la atención, y Ruiz Vargas, 2002, sobre el concepto de memoria operativa y sus componentes).

Resultados posteriores obtenidos por el mismo equipo permitieron poner de manifiesto también: (a) que la dificultad cognitiva de las tareas (p.ej., el hecho de que la narración no esté apoyada por dibujos) correlaciona negativamente con el grado de cohesión y coherencia de los relatos, tanto en el grupo esquizofrénico como en el de control; (b) que los fallos de control en la esquizofrenia pueden alcanzar también a algunas operaciones del procesador sintáctico (Anula, 1998), y (c) que los problemas de cohesión, coherencia y macroestructura (al igual que los déficits atencionales) constituyen un rasgo relativamente estable del funcionamiento de los pacientes con esquizofrenia, que se observa tanto en los episodios 
agudos del trastorno, como en fases de remisión de los síntomas clínicos (Insúa, Grijalvo y Huizi, 2000, 2001).

La interpretación del discurso alterado de los esquizofrénicos como resultado de un fallo generalizado del control cognitivo de la acción resulta convergente, por un lado, con la hipótesis de que los déficits atencionales y los fallos en el procesamiento estratégico o controlado de la información constituyen el núcleo del déficit cognitivo en la esquizofrenia y el principal marcador cognitivo de vulnerabilidad de esta enfermedad (Ruiz Vargas, 1987). La llamada hipótesis de la «automaticidad-control» planteada por este autor, se ha visto reforzada posteriormente por los datos neurocognitivos sobre la esquizofrenia, que confirman la existencia de déficits fronto-subcorticales convergentes con el déficit atencional (ver p.ej., Pantelis y Nelson, 1994). La hipótesis, por otro lado, resulta claramente convergente con algunas de las propuestas sobre la producción de discursos recogidas por autores como van Dijk (1980) y Tomlin y cols. (1997) que, como vimos en su momento, vinculaban la eficacia del discurso (i.e., su coherencia y su relevancia) a la correcta realización de operaciones de control tales como el mantenimiento en la memoria operativa de las representaciones correspondientes a las oraciones que van verbalizándose sucesivamente, la contrastación de cada una de ellas respecto al tópico y la intención originales, o la gestión referencial y del foco.

\section{Alteraciones del discurso en ancianos y en pacientes con demencia tipo Alzheimer.}

La relación funcional entre déficit de control y producción de discursos narrativos incoherentes (o alterados en su organización textual) observada con pacientes esquizofrénicos ha sido también puesta a prueba, ya en las últimas dos décadas, en estudios con ancianos y pacientes con demencia tipo Alzheimer, grupos ambos en los que se produce una reducción progresiva del control cognitivo de la acción derivada de cambios neurológicos (reducciones volumétricas, cambios metabólicos, disminución del riego cerebral y alteraciones neuroquímicas) que afectan a los lóbulos frontales (ver Anderson y Craik, 2000; Park y Schwarz, 2002).

En el caso concreto de los ancianos, Arbuckle y sus colaboradores (p.ej., Arbuckle y Gold, 1993) y algunos otros autores (p.ej. Zacks y Haser, 1994) han puesto de manifiesto que los cambios lingüísticos asociados al envejecimiento implican con mucha frecuencia pérdidas del tópico del discurso y disgresiones frecuentes en las conversaciones. La falta de control sobre los tópicos, y las dificultades para inhibir comentarios ex- 
temporáneos no se observan, sin embargo, en tareas narrativas más restringidas tales como la descripción de escenas presentadas visualmente o el relato de las vacaciones (Cooper, 1990; Gould y Dixon, 1993 -c.e. Burke, 1999-).

Como vimos también respecto a los esquizofrénicos, la impresión de que el habla de las personas mayores difiere significativamente del habla de las personas más jóvenes es común y generalizada, aunque no es siempre correcta. Según Ulatowska y Chapman (1994), las alteraciones discursivas consideradas como más característicamente asociadas a la edad son la reducción excesiva de información (en historias previamente oídas o leídas), la aportación a los relatos de información menos esencial y menos rica en conexiones, y la inclusión de información abundante de detalles no esenciales ni especialmente relevantes en los resúmenes de las narraciones. Conclusiones más positivas, sin embargo, se desprenden de los trabajos de Kemper y sus colaboradores (ver Kemper y Kemtes, 2000), que observan cómo incluso ancianos de mucha edad mantienen la capacidad para elaborar narraciones compuestas por episodios altamente jerarquizados y muy ricos en detalles, que son evaluadas más positivamente, son preferidas por los oyentes y son más fáciles de recordar que las de hablantes adultos más jóvenes.

Los informes clínicos de casos y la propia observación común dan cuenta de cambios asociados a la edad en el uso del lenguaje que pueden implicar tanto laconismo como verborrea, así como un aumento del lenguaje autorreferido e irrelevante. En trabajos que utilizan índices lingüísticos objetivos con los que se comparan narraciones y textos de distintos formatos con restricciones macroestructurales (p. ej., discurso procedimental), Ulatowska, Hayashi, Cannito y Fleming $(1985,1986)$ observaron una menor capacidad de los mayores para el relato de historias y dificultades pragmáticas para el establecimiento de presuposiciones y el uso de anáforas pronominales, tanto cuando las narraciones se presentaban de forma oral, como cuando se presentaban con el apoyo de imágenes. Resultados similares han sido obtenidos también en el estudio de Pratt et al. (1989), y en estudios translingüísticos de Juncos (Juncos, 1996; Juncos et al., 1995; Juncos y Pereiro, 1996; Pereiro y Juncos, 2000), quienes encontraron que, a medida que aumenta la edad, aumentan las dificultades en la utilización de los vínculos de cohesión y en el empleo de marcadores referenciales no ambiguos. Otros estudios (p.ej., Kemper, Rash, Kynette y Norman 1990; Flores, Belinchón y cols., en prensa) confirman que las personas de más edad elaboran textos poco cohesionados y presentan dificultades para establecer correctamente los antecedentes pronominales. Asimismo, recientemente, en un trabajo realizado por $\mathrm{Pe}$ - 
reiro y Junco (2000) en el que participaron grupos de adultos sanos con edades comprendidas entre los 40 y 91 años se obtuvieron correlaciones negativas significativas entre la eficacia en el establecimiento y mantenimiento de la referencia cohesiva, y la capacidad de almacenamiento y de «puesta al día» de la información procesada en la memoria operativa (o capacidad de control de la información durante el discurso).

En el caso de pacientes con demencia tipo Alzheimer, los fallos en el discurso que son más fácilmente detectados por los familiares se refieren al abuso de términos deícticos como «ese» o «eso», la ambigüedad referencial y la ausencia de relación cohesiva entre las oraciones, el incremento de repeticiones y redundancias, los cambios inesperados de tópico y los problemas para mantener el foco. A diferencia de los relatos de ancianos no demenciados, las narraciones de los pacientes con Alzheimer aportan información sobre el marco pero no sobre otras unidades narrativas estructuralmente básicas (episodio, resolución, etc.). Los relatos de actividades que exigen también un orden rígido de las secuencias se ven también afectados. El análisis de las conversaciones espontáneas muestran grandes dificultades también en la gestión del tópico y del foco (dificultades para iniciar, mantener y cambiar ordenadamente de tema), conservando los pacientes cierta capacidad autocrítica sobre sus problemas en las fases iniciales de la enfermedad (ver Ehrlich, 1994; Kemper y Kemtes, 2000).

\section{Alteraciones del discurso en pacientes con lesión unilateral del hemisferio izquierdo o derecho}

La comparación de las características del discurso de pacientes con lesiones unilaterales del hemisferio izquierdo o derecho, y con otros traumatismos craneales (close-head injuries) ofrecen también evidencia potencialmente de interés para los modelos neurocognitivos del discurso, en la medida en que pudieran revelar la posible disociación entre los procesos encargados de la gestión de los problemas específicamente discursivos (como la gestión temática, referencial o del foco) respecto de procesos de más bajo nivel correspondientes al dominio gramatical.

Con tareas narrativas de distinto tipo (relatos espontáneos, descripción de historias presentadas mediante dibujos, repetición de historias leídas por el examinador y discurso procedimental), los datos obtenidos por distintos autores (ver p.ej., Bloom, 1994; Coelho, Liles y Duffy, 1994) han revelado una preservación relativa de los aspectos más globales de la estructura del texto en los pacientes lesionados en áreas de Broca y Wer- 
nicke (hemisferio izquierdo), y una afectación más severa en los lesionados en el hemisferio derecho y con otros traumatismos craneales. Así, en los relatos de los pacientes afásicos (en los que se confirmaron los problemas fonológicos y morfosintácticos) se observaba una cierta reducción de la cantidad y diversidad de los vínculos cohesivos (con preferencia por la conectiva «y» frente a otras conectivas), una fuerte dependencia de expresiones deícticas de referencia, y errores pronominales ocasionales. En los relatos de los lesionados en el hemisferio derecho, sin embargo, eran significativamente más frecuentes las expresiones con referentes ambiguos, las expresiones deícticas y el empleo de sintagmas nominales definidos (grupos nominales fóricos, en términos de Rochester y Martin, 1979) en la introducción de referentes nuevos. En los pacientes con otros traumatismos cráneo-encefálicos, la generación original de historias estaba gravemente afectada, aunque la capacidad para repetir episodios de historias previamente oídas se mantenía preservada; el empleo de vínculos de cohesión estaba también drásticamente disminuido y, como en el caso de los esquizofrénicos, la cohesión léxica resultaba preferida sobre la referencial; la gestión y establecimiento de la referencia estaba también alterada. Todo ello sugiere conjuntamente, que la producción de discursos coherentes y cohesionados comporta una implicación cerebral bilateral, idea ésta que, sin poder considerarse trivial, no hace sino confirmar la complejidad neurocognitiva de esta forma de actividad verbal.

\section{Alteraciones del discurso en personas con trastornos del espectro autista}

En los últimos años, la identificación diagnóstica de personas con trastornos del espectro autista (TEA) y buenas capacidades cognitivas y verbales (personas con síndrome de Asperger y con trastorno autista sin retraso mental asociado -TA-) ha permitido también someter a prueba la hipótesis que sostiene que la alteración en la capacidad de atribuir estados mentales a otros y a uno mismo (capacidades de teoría de la mente) pueden también determinar algunos fallos significativos en la relevancia y la coherencia de los discursos narrativos (p.ej., en el manejo de la foricidad).

El déficit aparentemente específico de las personas con TEA en la elaboración y manejo de inferencias mentalistas (sobre la emoción y creencias de otros) está perfectamente avalado por los datos experimentales de las últimas dos décadas (ver Baron-Cohen, Tager-Flusberg y Cohen, 2000 para una revisión). Sin embargo, el estudio empírico de la competencia (o incompetencia) narrativa de este grupo es todavía incipiente. 
El escaso empleo de referencias endofóricas, y la alta proporción de referencias ambiguas fue observada por Fine y cols. (1994) en uno de los primeros estudios realizados con este tipo de población. La gran cantidad de episodios incompletos en las historias de un grupo con TA, la alta variabilidad del grupo en cuanto a número de episodios generados, la inserción de información irrelevante y los frecuentes errores presuposicionales (p.ej., en el manejo de grupos fóricos) han llevado a Landa y cols. (1995) y más recientemente a Solomon (2004), a concluir que las personas con TEA poseen la capacidad de generar relatos estructurados aunque parecen fallar en el cálculo de la relevancia. Los fallos en la relevancia, que indican una dificultad para tomar en consideración las necesidades informativas del interlocutor, se interpretan como un posible reflejo de déficit en teoría de la mente, pero podrían vincularse también con la conocida dificultad de las personas con TEA para integrar información en tareas cognitivas de alto nivel (coherencia central). Sin embargo, como han argumentado Martin y McDonald en un trabajo reciente (2003), el valor explicativo real de esta clase de hipótesis -como en realidad el valor de las que apelan a déficits ejecutivos o de control- es todavía discutible. Los índices utilizados actualmente en el análisis de los discursos desviados ( $y$, en general, en el estudio de las alteraciones pragmáticas) no permiten diferenciar entre grupos patológicos entre sí, y tampoco dirimir entre estas hipótesis alternativas, resultando por tanto urgente el diseño de otros índices y tareas que aporten evidencia crucial.

\section{Conclusiones}

El estudio de discursos desviados, o con fallos atribuibles a déficits cognitivos conocidos (de control ejecutivo, de teoría de la mente o de otras clases), tiene una tradición ya larga pero pocos resultados de interés fuera del ámbito clínico (esto es, fuera de la comprensión de los cuadros patológicos en sí mismos).

Hemos señalado las dificultades inherentes al estudio empírico del discurso, dificultades que se hacen más evidentes en la medida en que el objeto que pretendemos estudiar implica la participación integrada de procesos cognitivos modulares y centrales, situándose así en la intersección entre el pensamiento y el lenguaje.

El carácter intencional, cooperativo, contextualizado y supraoracional del discurso, exige una investigación interdisciplinar que permita estudiar tanto los procesos como las representaciones implicados en la producción de los mismos. Representaciones y procesos implicados en lo que 


\section{Alteraciones del Relato}

se denomina la «conceptualización» del discurso suponen adentrarnos en la cognición de orden superior y tener que integrar modelos generales de funcionamiento cognitivo con modelos específicos de producción y comprensión del lenguaje.

Es desde la Lingüística desde donde surgen las propuestas más interesantes con respecto a la producción del discurso. Los primeros trabajos de van Dijk (1980) y los de Beaugrande (1980) han dado paso a propuestas como la de Tomlin et al. (1997) quienes especifican los problemas fundamentales que tiene que enfrentar un hablante a la hora de construir un discurso y que hemos detallado previamente: la integración del conocimiento y la gestión de la información.

Estos problemas se van a poner en evidencia cada vez que algo falle, cada vez que el hablante no consiga resolver con eficacia las distintas tareas que implican la gestión de la información y la integración del conocimiento; de ahí la importancia que tiene el estudio de las alteraciones del discurso que muestran poblaciones con distintas patologías, casos únicos en los que poner a prueba hipótesis concretas.

Sin embargo, y a pesar de existir aproximaciones teóricas que dan cuenta de la complejidad de procesos y representaciones que implica la producción de los discursos, la investigación empírica se ha centrado en el análisis de la organización intratextual en los niveles fundamentales propuestos por la Lingüística (cohesión, coherencia y macroestructura), incluso cuando desde la propia disciplina se ha señalado que la textualidad no es una propiedad intrínseca de los textos sino que depende de condiciones definidas por los estados de conocimiento y expectativas que los hablantes y los oyentes comparten sobre una determinada realidad.

Así, surgen una serie de estudios empíricos con grupos de sujetos con diversas patologías que afectan a funciones o a mecanismos supuestamente implicados en la producción de los discursos (atención, memoria, teoría de la mente, etc.) utilizando índices derivados de dichas nociones teóricas aportadas por la Lingüística textual.

Las investigaciones sobre los discursos de los sujetos con esquizofrenia han venido a confirmar que el hablante (esquizofrénico o no) procesa los significados contenidos en las expresiones haciendo elecciones en distintos sistemas de lenguaje, y que la producción de textos coherentes implica la toma de decisiones adecuada en cada uno de estos diferentes sistemas. En los sujetos con esquizofrenia se producirían déficits de control que reducen la capacidad para la planificación y gestión del discurso, alcanzando estos fallos también a algunas operaciones del procesador sintáctico y constituyendo un rasgo relativamente estable e independiente de la sintomatología clínica de estos pacientes. 
Los estudios con ancianos y sujetos con demencia tipo Alzheimer también han demostrado la relación funcional que existe entre los déficits en los mecanismos de control de la información y la producción de discursos narrativos incoherentes, evidenciando dificultades también en la gestión referencial, en la gestión temática y en la gestión del foco. Por su lado, los estudios realizados con pacientes con lesiones cerebrales en los hemisferios derecho o izquierdo han señalado la implicación cerebral bilateral en la generación de discursos cohesionados y globalmente coherentes, poniendo en evidencia una vez más la complejidad cognitiva de los procesos de producción del lenguaje. Estudios recientes con personas con TEA han concluido que el tipo de discurso que estos producen indica dificultades en la gestión referencial lo que se interpreta como un posible reflejo de déficits en teoría de la mente.

Contrastados con los modelos teóricos aportados desde la Lingüística textual sobre la producción del discurso, los estudios de discursos desviados han servido para confirmar el importante papel de algunos mecanismos cognitivos de control (como la atención y la memoria operativa) de cara a garantizar la coherencia y relevancia de los textos. Metodológicamente, la importancia funcional de este control refuerza la impresión de mayor utilidad (para la investigación empírica de estos asuntos) de las tareas que imponen restricciones macroestructurales fuertes a la tarea de organización intratextual (como las narraciones y repeticiones de historias), en detrimento de las tareas menos constreñidas (como la conversación no estructurada o la descripción de escenas), y confirma el valor para la investigación textual de patologías neuropsiquiátricas específicas tales como la esquizofrenia, las demencias tipo Alzheimer y otras.

Los índices derivados de nociones teóricas como las de cohesión, coherencia y macroestructura, si bien se han demostrado sensibles a la hora de objetivar los rasgos que diferencian los discursos juzgados como «normales» (producidos por hablantes sin patologías, en condiciones habituales), de aquéllos que son juzgados como «desviados» (producidos por hablantes con patologías previas, o por hablantes sanos en condiciones cognitivas desfavorables -control reducido por el estrés, la fatiga o la atrofia de los lóbulos frontales asociada al envejecimiento-), no han permitido obtener patrones diferenciados de alteración asociados a los distintos trastornos de origen.

El valor potencial de estos índices para la diferenciación lingüística de los grupos y para la propia validación empírica de procesos y distinciones contemplados en los modelos actuales sobre el discurso parece, así, haber tocado techo. Se precisan nuevos índices y estrategias metodológicas, sensibles a las potenciales diferencias en el modo en que se ejecutan 


\section{Alteraciones del Relato}

en tiempo real los procesos del discurso en los distintos grupos de pacientes, y capaces de penetrar en la compleja realidad funcional de esos procesos, que por el momento «continúa esquivando, como el unicornio, a todos los que tratan de capturarla» (Hoffman y cols., 1982).

\section{Notas}

1 Para una acotación más precisa de los términos "narración", "relato" y «discurso", ver Igoa (en este mismo volumen).

\section{Referencias bibliográficas}

Anderson, A., Garrod, S.C. y SANFord, A.J. (1983). The accessibility of pronominal antecedents as a function of episode shifts in narrative text. Quarterly Journal of Experimental Psychology 35A, 427-440.

ANDERSON, N. y CrAIK, F.I.M. (2000). Memory in the aging brain. En E. Tulving y F.I.M. Craik (Eds.), The Oxford Handbook of Memory. Oxford: Oxford University Press.

ANDREASEN, N.C. (1979a). Thought, language and communication disorders. Clinical assessment, definition of terms and evaluation of their reliability. Archives of General Psychiatry, 36, 1315-1323.

AndREASEn, N.C. (1979b). Thought, language and communication disorders. Diagnostic significance. Archives of General Psychiatry, 36, 1325-1330.

Andreasen, N.C., Hoffman, R.E. y Grove, W.M. (1985). Mapping abnormalities in language and cognition. En A. Alpert (Ed.), Controversies in schizophrenia: changes and constancies. Nueva York: Guilford Press.

AndRIEssen, J., DE SMEDT, K. y Zock, M. (1996). Discourse Planning: Empirical Research and Computer Models. En T. Dijkstra y K. de Smedt (Eds.), Computational Psycholinguistics (pp. 247-278). Londres: Psychology Press.

Anula, A. (1998). La capacidad lingüistica en la esquizofrenia: Estudio sintáctico sobre la producción de oraciones en el discurso esquizofrénico. Tesis doctoral no publicada. Universidad Autónoma de Madrid.

ARBUCKLE, T. y Gold, D. (1993). Aging; inhibition y verbosity. Journal of Gerontology: Psychological Sciences, 48, 225-232.

Baron-Cohen, S., TAger-Flusberg, H. y Cohen, D. (2000). Understanding other minds. Oxford: Oxford University Press. (2. ${ }^{\mathrm{a}}$ ed.).

Beaugrande, R. DE (1980). Text, Discourse and Process. Toward a multidisciplinary science of text. Norwood, NJ: Ablex.

Beaugrande, R. DE y Dressler, W. (1981). Introduction to Text Linguistics. Londres: Longman (Trad. cast. Introducción a la lingüística del texto. Barcelona: Ariel, 1997).

BELINCHÓN, M. (1988). Hacia una caracterización empírica del lenguaje esquizofrénico. Estudios de Psicología 33-34, 157-189.

Belinchón, M., IgOA, J.M. y Rivière, A. (1992). Psicología del lenguaje. Investigación y teoría. Madrid: Trotta. Cap.15.

Benson, D.F. (1973). Psychiatric aspects of aphasia. British Journal of Psychiatry, 123, $555-556$ 
Berman, R. y Slobin, D. (1994). Relating events in narrative: A crosslinguistic developmental study. Hillsdale, N.J.: Erlbaum.

Bleuler, E. (1911/1960). Demencia precoz o el grupo de las esquizofrenias. Buenos Aires: Hormé.

Bloom, R. (1994). Preface. En Bloom, R.; Obler, L.; DeSanti, S y Ehrlich, J. (Eds.) Discourse Analysis and Applications. Studies in Adult Clinical Populations (pp. ix-xiii). Hove, UK: LEA.

Brown, R. (1973). Schizophrenia, language and reality. American Psychologist, 28, 395403.

Brown, G. y Yule, G. (1983). Discourse Analysis. Londres: Cambridge University Press (Trad. cast. Análisis del Discurso. Madrid: Visor, 1993.).

Chafe, W. (1979). The flow of thought and the flow of language. En T. Givon (Ed.), Syntax and Semantics 12: Discourse and Syntax (pp. 159-181). Nueva York: Academic Press.

CHAFE, W. (1980). The deployment of consciousness in the production of a narrative. En W. Chafe (Ed.), The pear stories. Norwood, NJ: Ablex.

Chafe, W. (1987). Cognitive constraints on information flow. En R. Tomlin (Ed.), Coherence and Grounding in Discourse (pp. 21-51). Amsterdam: John Benjamins.

Chafe, W. (1994). Discourse, Consciousness, and Time. Chicago: The University of Chicago Press.

CHAIKA, E. (1974). A linguistics looks at «schizophrenic» language. Brain and Language $1,257-276$

ChaIKa, E. (1981). How shall a discourse be understood?. Discourse Processes, 4, 71-88.

CHAIKA, E. (1982). A unified explanation for the diverse structural deviations reported for adult schizophrenics with disrupted speech. Journal of Communication Disorders, 15, 167-189.

Chaika, E., Lambe, R. y Alexander, P. (1982) Cohesion in normal and psychotic narration. Comunicación presentada en «The Linguistic Society of America». Annual Meeting en San Diego (manuscrito no publicado).

Coelho, C., Liles, B. y Duffy, R. (1994). Cognitive Framework: A Description of Discourse Abilities in Traumatically Brain-Injured Adults. En Bloom, R.; Obler, L.; DeSanti, S y Ehrlich, J. (Eds.) Discourse Analysis And Applications. Studies in Adult Clinical Populations (pp. 95-110). Hove, UK: LEA.

EHRLICH, J. (1994). Studies of discourse production in adults with Alzheimer's disease. En Bloom, R.; Obler, L.; DeSanti, S y Ehrlich, J. (Eds.) Discourse Analysis and Applications. Studies in Adult Clinical Populations (pp. 149-160). Hove, UK: LEA.

Fine, J., Bartolucci, G., Szatmari, P. y GinsberG, G. (1994). Cohesive discourse in pervasive developmental disorders. Journal of Autism and Developmental Disorders, 14, 315-329.

Flores, V., Belinchón, M., Olivar, J.S. y De la Iglesia, M. (en prensa). Evaluación del deterioro de las habilidades lingüísticas en ancianos: Un estudio empírico. Anuario de Psicología.

Fodor, J. (1983). The modularity of mind. Cambridge, MA: The MIT Press. (Trad. cast. La modularidad de la mente. Madrid: Morata, 1986)

Fromkin, V. (1975). A linguistic look at "A linguistic looks at "schizophrenic" language». Brain and Language, 2, 498-503.

GARROD, S.C. y SANFORD, A.J. (1982). The mental representation of discourse in a focused memory system: implications for the interpretations of anaphoric noun phrases. Journal of Semantics 1, 21-41 
Gerson, S.N., Benson, D.F. y Frazier, S.H. (1977) Diagnosis: Schizophrenia vs. posterior aphasia. American Journal of Psychiatry, 134, 966-969.

Givón, T. (Ed.). (1983). Topic Continuity in Discourse: A Quantitative Cross-Language Study. Amsterdam: John Benjamins.

Givón, T. (1991). Serial verbs and the mental reality of «events»: Grammatical vs. cognitive packaging. En E. Traugott y B. Heine (Eds.), Approaches to Grammaticalization (Vol. 1, pp. 81-127). Amsterdam: John Benjamins.

Givón, T. (1992). The grammar of referential coherence as mental processing instructions. Linguistics 30, 5-55.

HALlidAY, M. (1967a). Notes on transitivity and theme in English. Journal of Linguistics 3, 199-244

HALlidAY, M. (1967b). Intonation and Grammar in British English. La Haya: Mouton.

HALlidAY, M. (1970). Language structure and language function. En J. Lyons (Ed.), New Horizons in Linguistics. Harmondsworth: Penguin. (Trad. cast. Nuevos horizontes de la Lingüística. Madrid: Alianza).

Halliday, M. (1973). Explorations in the Function of Language. Londres: Arnold.

HALLIDAY, M. (1975). Learning how to mean: Explorations in the development of language. Nueva York: Elsevier (Trad. cast. Exploraciones sobre las funciones del lenguaje. Barcelona: Editorial Médica y Técnica.).

Halliday, M. (1976). Theme and information in the English clause. En G. Kress (Ed.), Halliday: System and Function in Language (pp. 174-188). Londres: Oxford University Press.

HALLIDAY, M. (1985). Introduction to Functional Grammar. Londres: Arnold

HALlidAY, M.A.K. y HASAN, R. (1976). Cohesion in English. Londres: Longman.

HANKAMER, J. y SAG, I. (1976). Deep and surface anaphora. Linguistic Inquiry 7, 391-428

HARVEY, P.D. (1983). Speech competence in maniac and schizophrenic psychoses: The association between clinically rated thought disorder and cohesion and reference performance. Journal of Abnormal Psychology, 92, 368-377.

HAVILAND, S.E. y ClaRK, H.H. (1974). What's new? Acquiring new information as a process in comprehension. Journal of Verbal Learning and Verbal Behaviour 13, 512 521.

HоввS, J.R. (1978). Why is discourse coherent? Technical Note, 176. Menlo Park, CA: SRI International.

HobBs, J.R. (1979). Coherence and coreference. Cognitive Science, 3, 67-90.

HoвbS, J.R. (1983). Why is discourse coherent? En F. Neubauer (Ed.). Coherence in natural language texts. Hamburgo: Helmut Buske Verlag.

Hoffman, R., Kirstein, L., Stopek, S. y Ciccheti, D.V. (1982). Apprehending schizophrenic discourse: A structural analysis of the listener's task. Brain and Language, 15, 207-233.

IGOA, J.M. y GARCíA-AlBEA, J.E. (1999). Unidades de planificación y niveles de procesamiento en la producción del lenguaje. En M. de Vega y F. Cuetos (Coords.) Psicolingüística del Español. Madrid: Trotta.

InsÚA, P., GRIJALVO, J. y HuIZI, P. (2000). «Psycholinguistic processes and schizophrenia: Two years follow-up». Poster presentado en el 27th International Congress of Psychology, organizado por la Swedish Psychological Association. Estocolmo, Suecia.

InSÚA, P., GRIJALVo, J. y Huizi, P. (2001). Alteraciones del lenguaje en la esquizofrenia: Síntomas clínicos y medidas psicolingüísticas. Revista de la Asociación Española de Neuropsiquiatría, 78, pp. 27-50. 
Kemper, S. y Kemptes, K. (2002). El envejecimiento y la producción y comprensión de mensajes. En D. Park y N. Schwarz (Eds.), Envejecimiento cognitivo. Madrid: Panamericana.

Kemper, S., Rash, S., Kynette, D. y Norman, S. (1990). Telling stories: The structure of adult's narratives. European Journal of Cognitive Psychology, 2, 205-228.

KraEPELIN, E. (1919/1971). Dementia praecox and paraphrenia. Nueva York: Robert E. Krieger Publish. Co. Inc.

Krauss, R. M. y GLucksberg, S. (1969). The development of communication as a function of age. Child Development, 40, 255-266.

LAMBRECHT, K. (1994). Information structure and sentence form. Topic, focus, and the mental representation of discourse referents. En Cambridge Studies in Linguistics (Vol. 71). Cambridge: Cambridge University Press.

LANDA, R. (1995). Social language use in Asperger syndrome and high-functioning autism. En A. Klin, F.R. Volkmar y S. Sparrow (Eds.), Asperger syndrome. Nueva York: The Guilford Press.

LeCours, A.R. y VANier-Clement, H. (1976). Schizophasia and jargonaphasia: A comparative description with comments on Chaika's and Fromkin's respective looks at "schizophrenic" language. Brain and Language, 3, 516-565.

Levelt, W.J.M. (1982). Linearization in describing spatial networks. En S. Peters y E. Saarinen (Eds.), Processes, beliefs, and questions. Dordrecht: Reidel.

Levelt, W.J.M. (1989). Speaking. Cambridge, MA: The MIT Press.

Levelt, W.J.M. (1999). Producing spoken language. A blueprint of the speaker. En C.M. Brown y P. Hagoort (Eds.), The Neurocognition of Language. Oxford: Oxford University Press.

LONGACRE, R.E. (1976). An anatomy of speech notions. Lisse: Peter de Ridder.

MARTIN, I. y MCDONALD, S. (2003). Weak coherence, no theory of mind, or executive dysfunction? Solving the puzzle of pragmatic language disorders. Brain and Language, $85,451-466$

Obler, L., Au, R., Kugler, J., Melvold, J., Tocco, M. y Albert, M. (1994). Intersubject variability in adult normal discourse. En Bloom, R., Obler, L., DeSanti, S. y Ehrlich, J. (Eds.) Discourse Analysis and Applications. Studies in Adult Clinical Populations (pp. 15-28). Hove, UK: LEA.

PANTElis, Ch. y Nelson, H. (1994). Cognitive functioning and symptomatology in schizophrenia: The role of frontal-subcortical systems. En A. David y J.C. Cutting (Eds.), The Neuropsychology of Schizophrenia. Hove: LEA.

PARK, D. y SCHWARZ, N. (2002). Envejecimiento cognitivo. Madrid: Panamericana.

PARKIn, A.J. (1999). Exploraciones en Neuropsicología Cognitiva. Madrid: Panamericana.

Pereiro, A. y Juncos, O. (2000). Discurso narrativo en la vejez. Estudio sobre la referencia. Congreso de la Asociación Española de Lingüística Aplicada. Barcelona.

Perfetti, C.A. y Goldman, S.R. (1974). Thematization and sentence retrieval. Journal of Verbal Learning and Verbal Behaviour 13, 70-79.

Pratt, M. Boyes, C., Robins, S. y Manchester, J. (1989). Telling tales: Aging, working memory, and the cohesion of story retellings. Developmental Psychology, 25, 628-635.

Rochester, S. y MARTIn, J.R. (1979). Crazy talk: A study of the discourse of schizophrenic speakers. Nueva York: Plenum Press.

Rochester, S.R., Martin, J.R. y Thurstone, S. (1977). Thought process disorder in schizophrenia: The listener's task. Brain and Language, 4, 95-114.

Ruiz VARgas, J.M. (1987). Esquizofrenia. Un enfoque cognitivo. Madrid: Alianza. 


\section{Alteraciones del Relato}

Ruiz VARGAS, J.M. (1993). Atención y control: Modelos y problemas para una integración teórica. Revista de Psicología General y Aplicada, 46, 125-137.

Ruiz Vargas, J.M. (2002). Memoria y olvido: Perspectivas evolucionista, cognitiva y neurocognitiva. Madrid: Trotta

SEARLE, J.R. (1969). Speech Acts: An Essay in the Philosophy of Language. Cambridge: Cambridge University Press.

Siegel, A., Harrow, M., Reilly, F.E. y Tucker, G.T. (1976). Loose associations and disordered speech patterns in chronic schizophrenics. Journal of Nervous and Mental Disorders, 162, 105-112.

Solomon, O. (2004). Narrative introductions: Discourse competence of children with autistic spectrum disorders. Discourse Studies, 6 (2), 253-276.

Tomlin, R.S., Forrest, L., M.M., P. y KIM, M.H. (1997). Discourse Semantics. En T.A. van Dijk (Ed.), Discourse as Structure and Process. Discourse Studies: A Multidisciplinary Introduction: Vol I (pp. 63-111). Londres: Sage. (Trad cast. El discurso como estructura y proceso. Estudios sobre el Discurso I: Una introducción multidisciplinaria. Barcelona: Gedisa).

TUCKer, G.J. y Rosenberg, S.D. (1975). Computer content analysis of schizophrenic speech: A preliminary report. American Journal of Psychiatry, 132 (6), 611-616.

Ulatowska, H.K., Cannito, M., Hayashi, M. y Fleming, S. (1985). Language abilities in the elderly. En H.K. Ulatowska (Ed.), The aging brain: Communication in the elderly. Boston: College Hill.

Ulatowska, H.K. y Chapman, S. (1994). Discourse studies. En R. Lubinski (Ed.), Dementia and communication. (pp.115-132). Filadelfia: Decker.

VAN DiJK, T.A. (1980). Macro-Structures. An Interdisciplinary Study of Global Structures in Discurse, Cognitions and Interaction. Hillsdale, N.J.: Erlbaum.

VAN DiJK, T.A. (1983). La ciencia del texto. Barcelona: Paidós.

VAN DiJK, T.A. (1985). Semantic discourse analysis. En T.A. van Dijk (Ed.), Handbook of Discourse Analysis (Vol. 2, pp. 103-136). San Diego, CA: Academic Press.

van DiJk, T.A. (1997a). Discourse as Structure and Process. Discourse Studies: A Multidisciplinary Introduction. Vol I. Londres: Longman.

van Disk, T.A. (1997b). Discourse as Social Interaction. Discourse Studies: A Multidisciplinary Introduction. Vol II. Londres: Longman.

WykEs, T. y LEFF, J. (1982). Disturbed speech: Differences between maniacs and schizophrenics. Brain and Language, 15, 117-124. 